\title{
APPLICABILITY STUDY OF THE FIBER-OPTIC GYRO IN PISTON ENGINES DIAGNOSING PROCESS
}

\author{
Tomasz Lus ${ }^{1}$, Marek Lutowicz², Dominika Cuper ${ }^{3}$
}

\author{
Polish Naval Academy \\ E-mail: 1't.lus@amw.gdynia, ${ }^{2}$ m.lutowicz@amw.gdynia.pl, ${ }^{3}$ ratsusia@gmail.com
}

Received 2014-06-12, accepted 2014-09-09

The Polish Naval Academy has been involved in marine reciprocating combustion engines indication tests for many years. Results of researches aiming to diagnostic using of measurement of engine crankshaft unsteady angular speed are presented in the paper. Up to now, adequate accuracy of angular speed measurement had not been achieved to make proper diagnostic decision. Commercially, measurement of unsteady rotation speed has been used only in MAPEX -TV system (Torsional Vibration detector) dedicated to SULZER engines, which can detect only the one engine cylinder switch out of work without any mistakes. For several years, mostly in navigation, more often are used optic gyroscopes which work on the base of Sagnac effect, assuring angular speed measurements with resolution of $0.001 \%$. Such resolution is too high than needed in piston engines diagnostic, but range of measured rotation speed is much much lower than rpm of mediumor low-speed marine diesel engines. In scope of conducted research it was decided to build a model of Sagnac interferometer prepared to measure of instantaneous angular speed in range adequate to medium speed marine diesel engines. At rotational crankshaft speed equal $750 \mathrm{rpm} 1 \mathrm{mV}$ change in output voltage had been achieved for the difference of $0,4 \% \mathrm{sec}$ of rotational speed. Time of measurement is equal the time which need light ray to go through distance of $100 \mathrm{~m}$ fibber-optic line. In practice this method do not introduce any significant phase shifts and does not limit the number of samples per revolution.

Piston engine, indicating, rotational speed accuracy, diagnostics.

\section{Introduction}

The instantaneous angular speed measured with high resolution can be a very useful diagnostic parameter $[1,3,4,5]$ of marine diesel engine. A dominant influence on the angular acceleration has a total summarized moment of tangential forces which act on all engine crankshaft systems, and these in turn depend mainly on the mean indicated pressure of each cylinder.

In the research work currently carried out in Polish Naval Academy (PNA) it was decided to separate from the course of instantaneous speed acceleration induced by cyclic engine operation and from accelerations caused by uneven load of the engine and the governor operation [2]. In such tests the measuring system must provide sufficient resolution without the use of filtering and averaging. This paper presents of such method which could be applicable on marine diesel engines. 


\section{Methods of instantaneous angular speed measurement}

Very popular are the measurements of the angular instantaneous speed by using optical or inductive sensors with gear/teeth element arranged on the shaft. By calculating the angular speed derivative in time domain it is possible to determine the angular acceleration. Such attempts have been repeatedly made in the past but the results were subject to large errors.

In the PNA special system for measuring of the angular speed, insensitive to inaccuracies connected with the toothed element, has been developed. This error has been eliminated by expanding the measurement system for an additional sensor. Measurement of the time of the marker transition between two sensors spaced apart by an angle slightly less than the angle between the teeth has been done. Both sensors had detected the appearance of the same gaps between marks. Preliminary tests were carried out on the one cylinder engine type KM170. Results of these tests were very encouraging. Clean, undistorted waveforms had been obtained. As expected, the filtering and averaging have been unnecessary.

Lately it was decided to build the measuring system for the 6 cylinder SULZER engine type 6AL20/24. In the case of 6-cylinder engine unsteady of angular speed was significantly smaller and the accuracy of the method has proved to be insufficient.

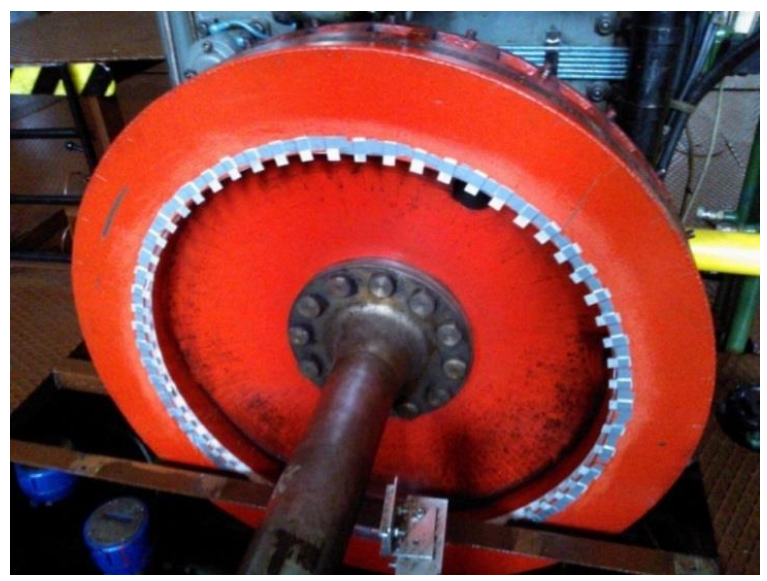

Fig. 1. Tags mounted on the SULZER type 6AL2024 engine flywheel

Arrangement of measuring stand on engine flywheel is shown in Fig. 1 and an example of a measurement result of the instantaneous angular speed at this engine is shown in Figure 2. 


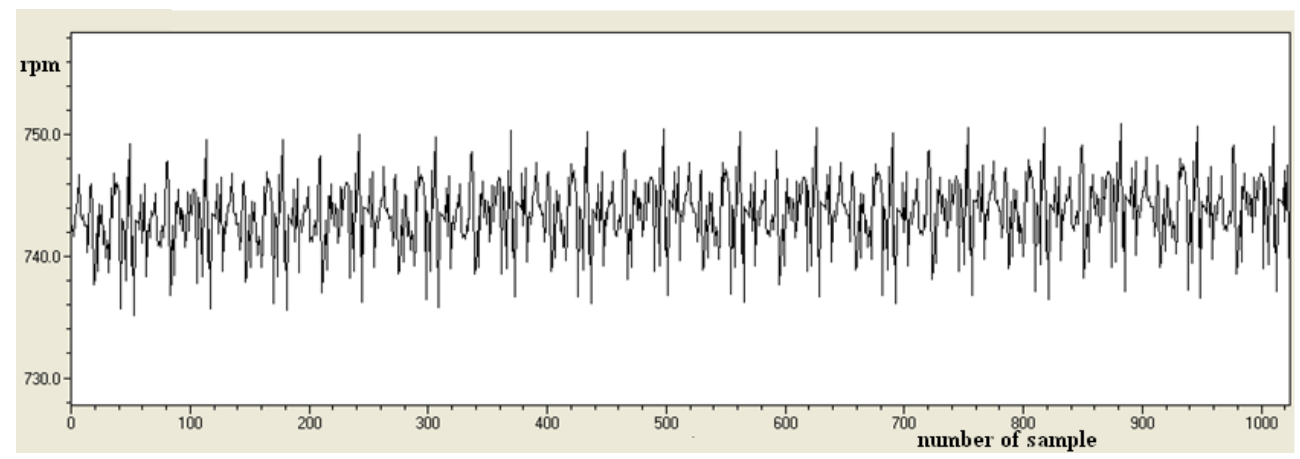

Fig. 2. An example of the measurements result of the SULZER engine 6AL20/24 type shaft angular speed between markers at a speed of $750 \mathrm{rpm}$ with no load

There is a presumption that the cause of interference could be vibration of the engine block which moved to the vibration of optical sensors. It was intended to measure the time of the marker transition between sensors spaced about $25 \mathrm{~mm}$ with resolution above 20000 then the displacement of the sensor for each 2.5 microns was recorded as a change in the time of 2 units. It was itself the source of unacceptable error.

The engine block vibrations caused by the cyclic operation of the engine and the surge of the sea can be eliminated by measuring the angular velocity or acceleration with respect to an inertial reference system, which in the simplest case can be weight freely suspended on the shaft.

Angular acceleration according to this method can be measured by seismic sensors of special construction mounted on the shaft as shown in Figure 3.

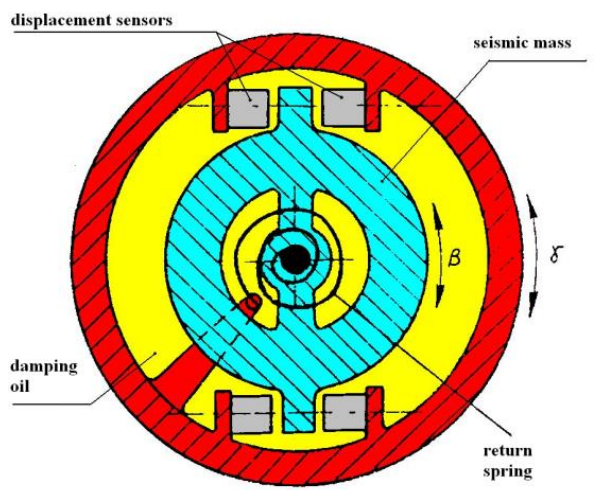

a)

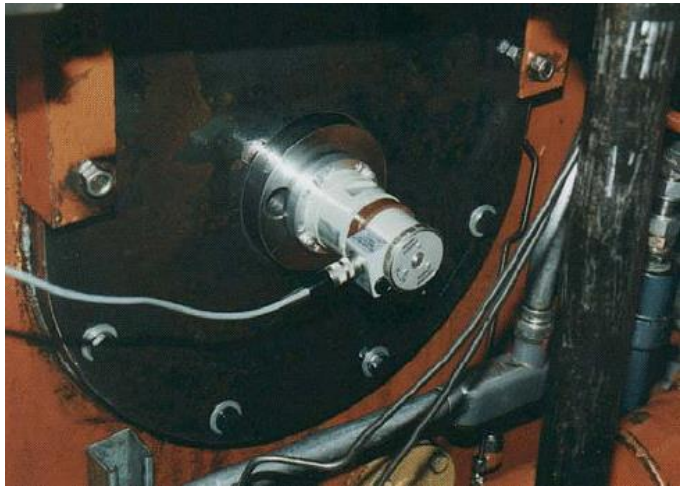

b)

Fig. 3. Schematic a) and view b) of Hottinger type torsjograpf mounted on the shaft end

The sensors are built on the same principles as the well known Geiger's torsiographs with mass drivable by a spring, which movement is measured relative to the housing directly connected to the shaft. The sensing element may be a 
piezoelectric element, inductive or capacitive. Thank to the fact that the mass is journalled in the center of gravity the transducers are not sensitive to vibrations of the measuring object. They do not measure absolute angular displacement of seismic mass, but relative twisting:

$$
\varphi=\beta-\gamma .
$$

The interior of the transducer is filled with silicone oil in order to introduce damping into the system corresponding to the relative speed and proportional to the vibration of the mass relative to the housing. Transducer itself shows a simple vibrating system whose frequency characteristics must be known, because it limits the scope of applicability of this transmitter, and is the source of the unequivocal of the results of measurement.

\section{Sagnac interferometer in angular speed measurement}

The most accurate measurements of the distance and the speed are performed by optical methods which measure interference with resolutions better than the wavelength of light. For example, a Michelson interferometer is so accurate that in $1960 \div 1983$ years it served as the definition of the SI meter. To measure of the angular velocity the Sagnac interferometer can be used. It is now mainly used in inertial navigation systems in aircrafts, submarines and missiles. Devices, using Sagnac interferometer, allows measurement of the angular velocity to a resolution of about $0.0010 /$ hour and are used as sensors for so-called optical gyroscopes. Due to the simplicity of some versions of these interferometers with slightly worse parameters they are so cheap that have been used even in toys.

Historically, the first practical implementation of the Sagnac interferometer is an interferometer RLG (Ring Laser Gyro). It consists of a helium-neon laser chamber, wherein the optical resonator is made of at least three mirrors. One of them is semi-permeable and through this two laser beams go out. After the change of one beam path through the prism so that it is parallel to the second light beam interference occurs. Bands are formed. In this interferometer Sagnac effect is used, which is characterized in that in the case of rotation of the interferometer about any axis perpendicular to the plane of the triangle formed by the laser beam the different transit times between the mirrors loop are formed resulting in two light beams propagating in opposite directions (clockwise and anticlockwise to loop rotation). So the phase difference $\Delta \Phi$ is formed by turning the interferometer and the apparent speed of beams, as in the Doppler phenomenon are V $+\mathrm{R} \omega$ and $\mathrm{V}$ $\mathrm{R} \omega$ where: $\omega$ is the speed of rotation around the axis of the interferometer, $\mathrm{V}$ is the velocity of light inside the interferometer.

The measurement of the phase difference can be obtained via image analysis of interference of both beams. Rotation on any axis perpendicular to the plane of the triangle formed by the laser beam moves interference bands in proportion to the angular velocity of the interferometer. Schematic view of such interferometer with ring resonator and the view of interference bands generated is shown in Figure 4. 


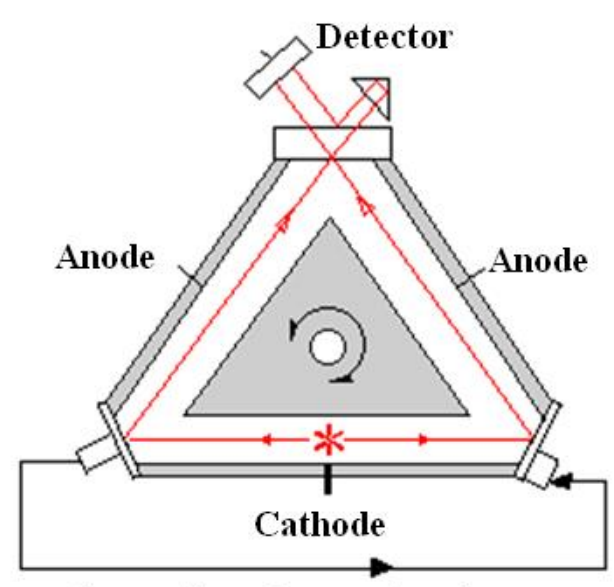

Correction of geometry changes

a)

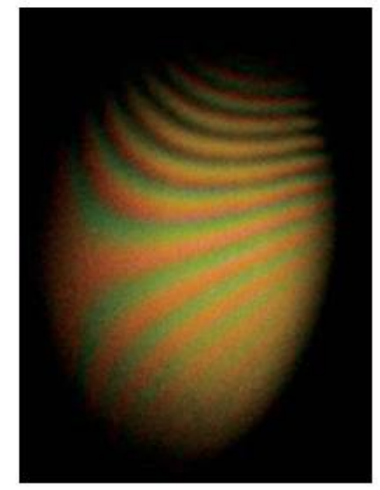

b)

Fig. 4. Schematic view a) of Sagnac interferometer and interference bands/fringes b) on the detector

This interferometer is insensitive to linear displacement and rotation with respect to any other axis perpendicular to the measurement axis. Although this is a forward-looking technology, due to the severity excludes amateur construction, RLG gyros were excluded from further consideration. It should be noted that it would be ideal sensor, because of the simplicity of calculations and the quality of the measurements.

Sagnac phenomenon is also used in gyroscopes with fiber-optic loop - FOG (Fiber Optic Gyro) as shown schematically in Figure 5.

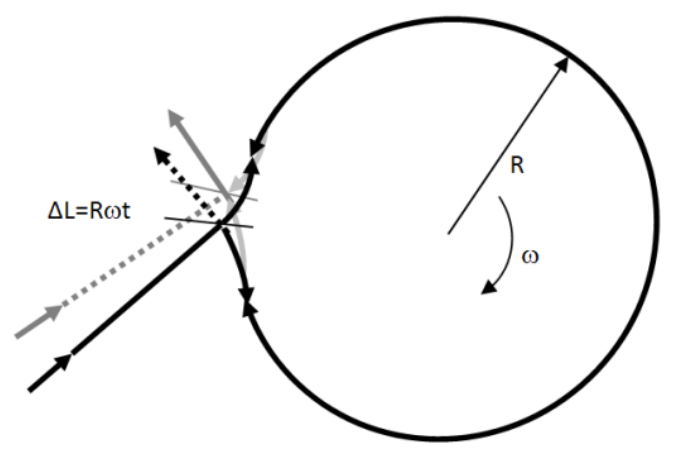

Fig. 5. Schematic of the Sagnac interferometer with fiber-optic loop

Light from a laser source before entering the fiber is separated in to two beams, one of which runs in accordance with the movement of the rotating angular speed $\omega$, and the other counterclockwise. During the course the beams interfere with each other. The rotational speed of the loop, similar as in RLG (Ring Laser Gyro) interferometer, has an impact on the phase shift between the beams propagating in opposite directions. 
Since both the beam comes from a single point does not arise interference fringes. Here the modulation subject is only brightness of light, and the difference in distance, which results from the rotation speed determines the nature of the interference. The intensity of the output light is measured with the photodiode. The dependence of the amplitude of the voltage across the photodiode as a function of the phase shift between the light beams was calculated with formula 1 .

$$
I=I_{0} \frac{(1+\cos (\Delta \varphi))}{2}
$$

where:

I - light wave intensity (voltage on the photodiode),

$\Delta \phi$ - phase shift.

In order to increase the measurement efficiency numbers of windings of the fiber are increased. Then the phase shift between the beams describes the formula 2.

$$
\Delta \phi=\frac{2 \pi L D \Theta}{\lambda c}
$$

where:

$\mathrm{L}$ - length of the fiber [m],

D - diameter of the coils [m],

$\lambda$ - light wave length $[\mathrm{m}]$,

$\mathrm{c}$ - velocity of light $300 \cdot 106[\mathrm{~m} / \mathrm{s}]$,

$\omega$ - angular velocity $[\mathrm{rad} / \mathrm{s}]$.

After converting the formula angular velocity $\Omega \pi$ has been determined for which $\Delta \phi=\pi$. This angular speed turns off the light at the output:

$$
\Omega_{\pi}=\frac{\lambda c}{2 L D}
$$

This speed rate determines the measurement range of the interferometer. Practically you can get any finite value of the $\Omega \pi$ choosing: a light source of a specific length, fiber length and diameter of the fiber loop.

Calculated intensity of the light wave as a function of the angular velocity is shown in Figure 6. 


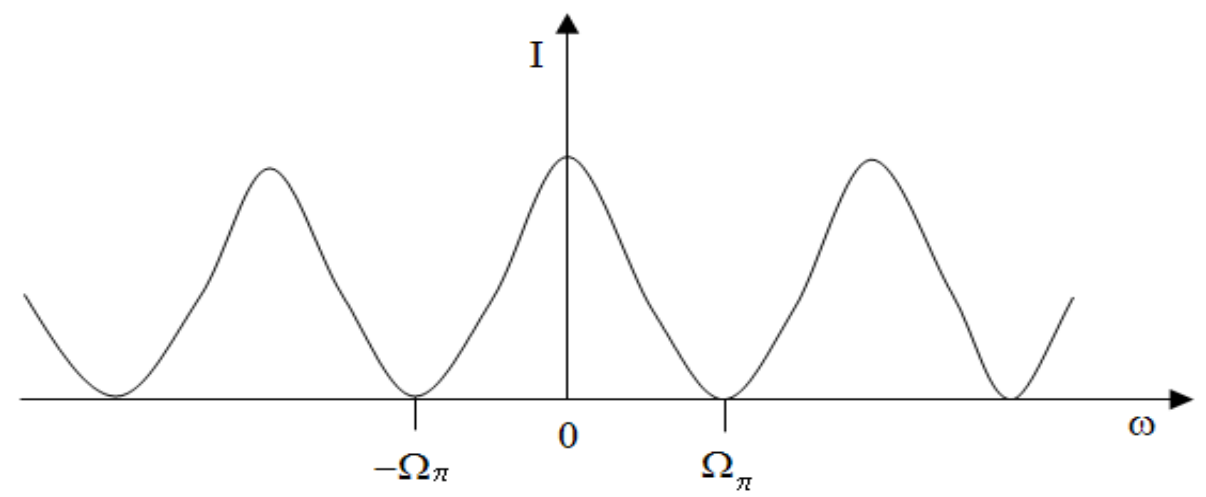

Fig. 6. Brightness of the light being interference effect as a function of the angular velocity

In the commercially available optical gyroscopes fibers of lengths of more than $2 \mathrm{~km}$ are used and optimize them into account to improve the accuracy particularly at extremely low speeds. Sample specifications of professional FOG type gyroscopes are presented in Table 1.

Table 1. Specifications of professional FOG type gyroscopes specified by the manufacturers [www.acielo.com, www.fizopika.ru]

\begin{tabular}{|l|c|c|c|c|c|}
\hline \multirow{2}{*}{$\begin{array}{l}\text { Type of } \\
\text { gyroscope }\end{array}$} & \multicolumn{3}{|c|}{$\omega_{\max }$} & \multicolumn{2}{c|}{ Random error } \\
\cline { 2 - 6 } & 100 & $\mathrm{rad} / \mathrm{s}$ & $\mathrm{rev} / \mathrm{min}$ & $\circ / \mathrm{h}$ & $\%$ \\
\hline Acielo FOG 24 & 1200 & 0,0058 & 0,0556 & 0,05 & 0,000042 \\
\hline Acielo FOG 52 & 1080000 & 5,24 & 50 & 10 & 0,00093 \\
\hline $\begin{array}{l}\text { Fizoptika } \\
\text { VG091A }\end{array}$ & & & & & 0,002 \\
\hline
\end{tabular}

As it is clear from the statement offered with FOG type gyroscopes for the intended use in navigation they are optimized to obtain resolution of less than $1 \%$ hour. This optimization is done at the expense of the measuring range which does not exceed $0.05 \mathrm{rev} / \mathrm{min}$ for high-performance gyroscopes Acielo type. Only the cheapest on the market and also the worst in terms of navigation gyroscope VG091A type has a measuring range of $50 \mathrm{rev} / \mathrm{min}$, which is close to the range required for the measurement of slow-speed marine diesel engines. In the case of medium speed marine diesel engines range as the gyroscope has is too small. It is possible to build a FOG type interferometer using typical elements of fiber optics used in telecommunications, connected according to the diagram shown in Figure 7. 


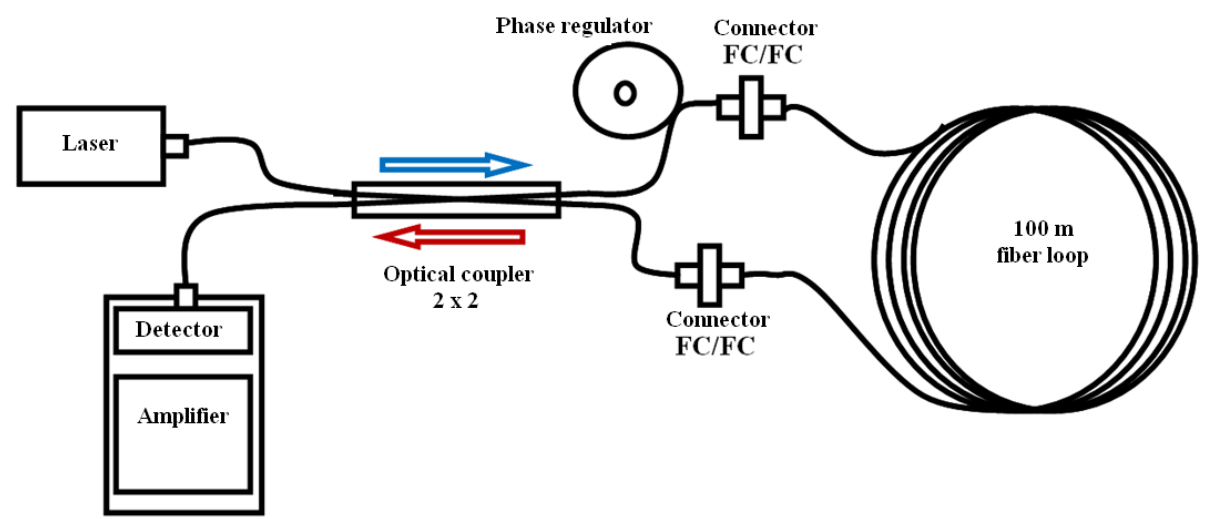

Fig.7. Schematic of FOG type gyroscope based on typical elements of telecommunications fiber optics

For the planned test bench it was assumed that the fiber can be wound on the existing shaft connecting the engine with brake with a diameter of $0.11 \mathrm{~m}$. The light source is a laser diode with a light wavelength of $1300 \mathrm{~nm}$, and the maximum angular velocity of the engine for which it is possible to explicitly transform the intensity of the light wave at the speed $\Omega \pi=1000 \mathrm{r} / \mathrm{min}$, ie $104.7 \mathrm{rad} / \mathrm{s}$ Transforming the formula 3 into a 4 it can be obtained correlation, which sets the required length of the fiber.

$$
\begin{aligned}
& L=\frac{\lambda c}{2 D \Omega \pi} \\
& L=\frac{1300 \cdot 10^{-9} \cdot 300 \cdot 10^{6}}{2 \cdot 0,11 \cdot 104,7}=17[\mathrm{~m}]
\end{aligned}
$$

Then the detector voltage varies as shown in Figure 8. It contains a constant component caused mainly by the unequal distribution of the light beam through the coupler and reflections from the points of discontinuity of the fiber.

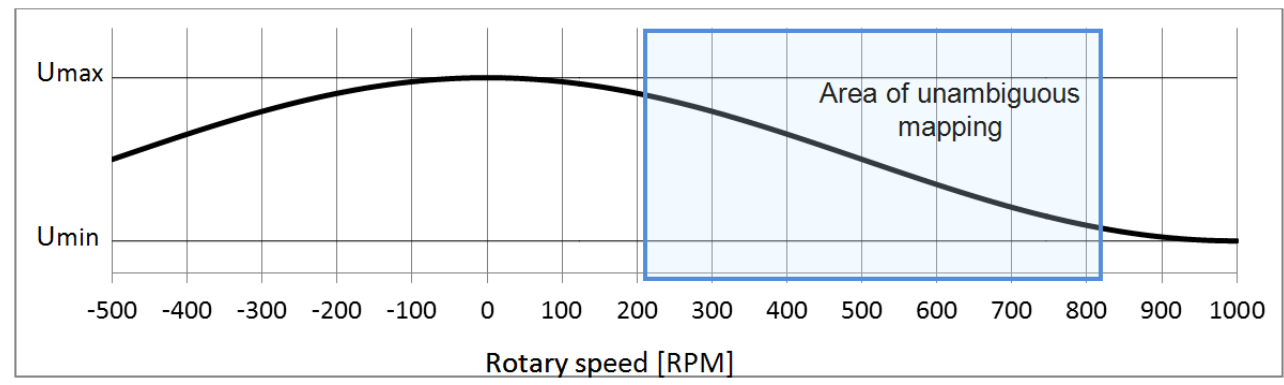

Fig. 8. Light intensity as a function of the rotary speed for the loop length of $17 \mathrm{~m}$ 
This voltage can be explicitly converted to a rotational speed according to the formula:

$$
n=\cos ^{-1}\left(\frac{U_{\max }-U_{\min }}{U-U_{\min }}\right) \frac{\omega_{\pi}}{\pi}
$$

where $\omega \pi$ is expressed in rev / $\mathrm{min}$.

Assuming that the measured speed rate falls within the range of 500 to 1000 $\mathrm{rev} / \mathrm{min}$ it may be adopted $\Omega \pi=500 \mathrm{rev} / \mathrm{min}$. Then the phase shift for the speed of $1000 \mathrm{rpm}$ is equal of $2 \pi$. Such a change can be achieved by extending of the fiber to $33.9 \mathrm{~m}$ Then for speeds in the range of about 100 to $400 \mathrm{rpm}$ formula of voltage dependence is described by equation 5, while in the range 600 to 900 on the photodiode voltage conversion speed is clearly described with the formula 6 .

$$
n=2 \Omega_{\pi}-\cos ^{-1}\left(\frac{U_{\max }-U_{\min }}{U-U_{\min }}\right) \frac{\omega_{\pi}}{\pi}
$$

This will provide a dabble increase in resolution. However, to accurately calculate the speed you need other methods to determine its approximate value to determine which formula should be used. In the area of about 400 to $600 \mathrm{rpm}$ due to the slight inclination and slope course the calculation of the clear value of speed is virtually impossible.

By extending the fiber to $170 \mathrm{~m}$ it can be obtained light intensity dependence which reaching the detector as shown in Figure 9.

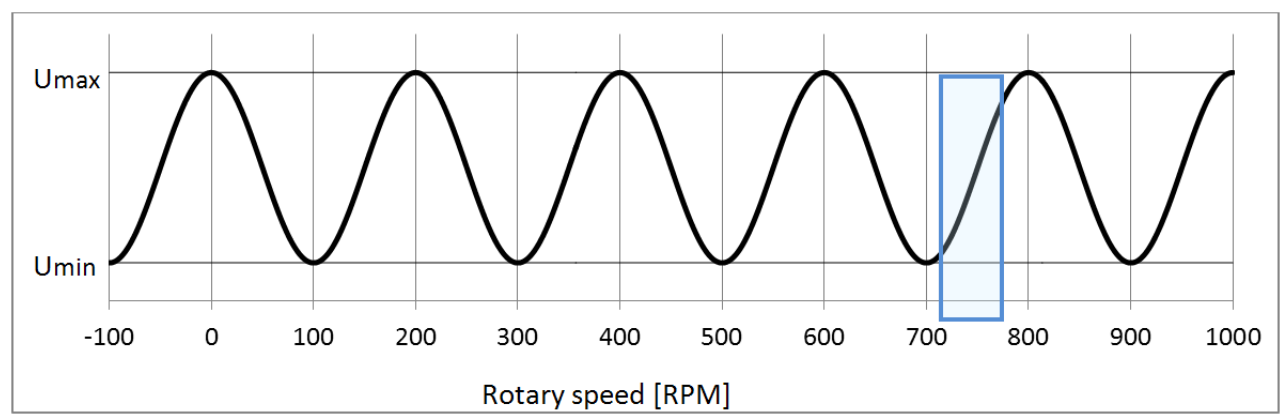

Fig. 9. Light intensity as a function of the rotary speed for the loop length of $170 \mathrm{~m}$

This time that will ensure 10 times increase in resolution, but unequivocal mapping of the photodiode voltage in the rotation speed is only possible in an range of about $\pm 30 \mathrm{rev} / \mathrm{min}$ according to of expected speed such as $750 \mathrm{rev} / \mathrm{min}$.

\section{Construction of the prototype}

Despite the technical potential, widely available optical gyroscopes are not working at the required speed range yet. For the purpose of this work it was decided to build the interferometer itself. $100 \mathrm{~m}$ a single mode optical fiber was bought with a set of fiber optic connectors, $2 \times 2$ beam splitter on a $50 \% / 50 \%$, the 
laser source and the light detector. Wiring diagrams of laser driver circuit and PIN diode amplifier are shown in Figure 10.

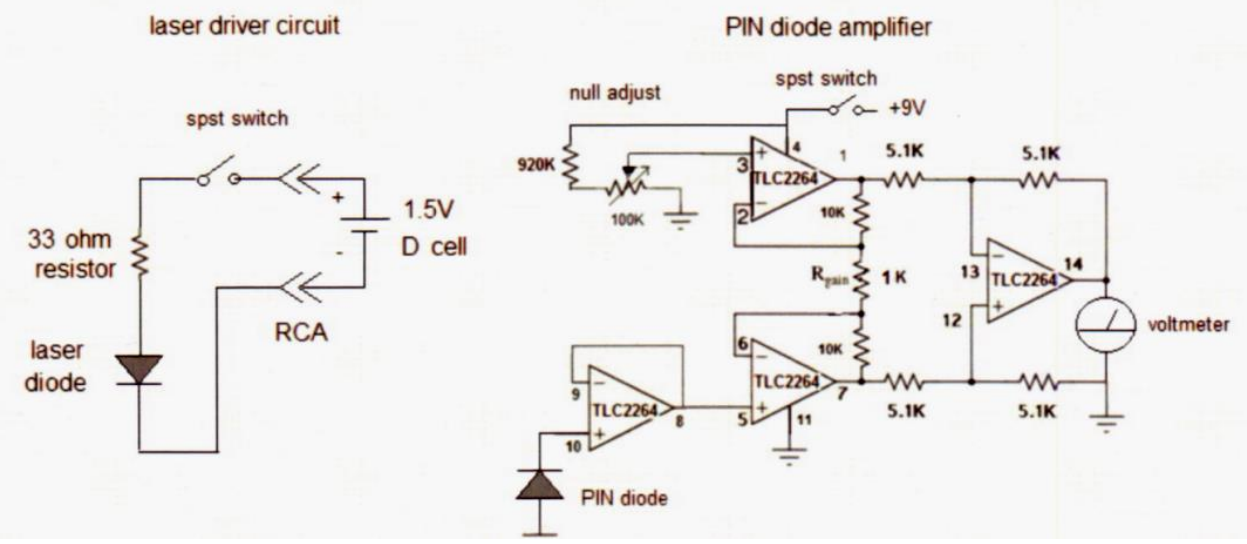

Fig. 10. Diagrams of laser driver circuit and PIN diode amplifier

Optical part of the fiber gyroscope was made by purchasing ready-made components by using only simple tools. Due to the lack of experience with the construction of this type of fiber optic equipment for experimental purposes in the prototype assembly ready-made aluminum platform was used - Figure 11.

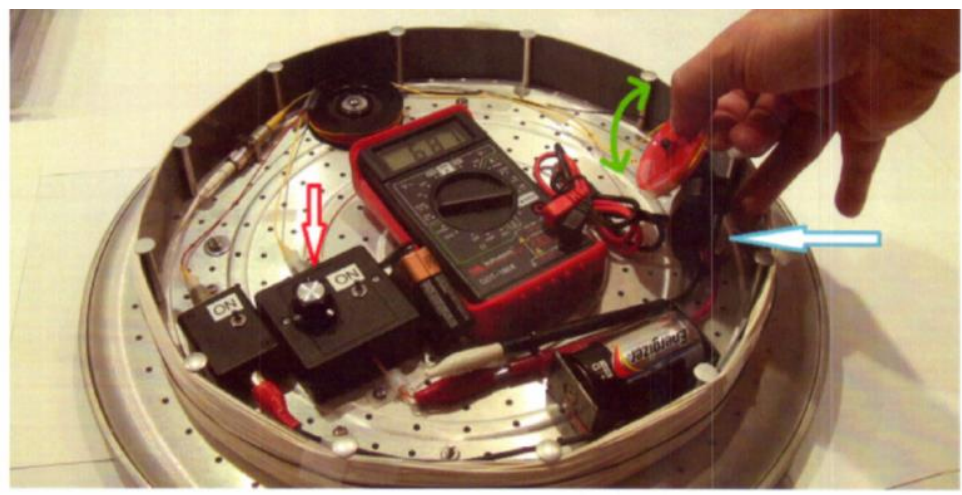

Fig.11. Finding a minimum of the voltage by adjusting the phase shifter

\section{Estimating the sensitivity}

To estimate the sensitivity of the built gyroscope equation for the phase shift in the fiber optic gyroscope was used and the angular velocity was determined $\Omega \pi$ for which the phase shift of $\Delta \varphi=\pi$, caused turns off the interfering beams. The formula 3 has been used.

Obtained angular velocity value is:

$$
\Omega_{\pi}=\frac{1,3 \times 10^{-6} \times 30 \times 10^{6}}{2 \times 100 \times 0,32}=6,09 \frac{\mathrm{rad}}{\mathrm{s}}
$$

which is approximately $349.5^{\circ} / \mathrm{sec}$. 
Since the maximum voltage range is about $850 \mathrm{mV}$, the obtained sensitivity is:

$$
349.5 / 850=0.41^{\circ} / \mathrm{sec} / \mathrm{mV}
$$

what ensures that the voltage of $1 \mathrm{mV}$ corresponds to the speed difference of about $0.4^{\circ} / \mathrm{sec}$.

This calculation is not accurate. The actual measurements may be slightly different, as the sensitivity is largely dependent on many parameters, among others, the damping in the joints, equal distribution of the beam and mainly on the intensity of the laser current, the controller set point phase and photodiode amplifier gain.

In the nearest future the special gyroscope set will be build and mounted on the shaft connecting engine with the hydraulic brake and laboratory tests will be carried out.

\section{Conclusions}

From authors point of view among many analyzed methods of rotational speed measuring the most promising seems to be FOG gyroscopes. They enables rotational speed measurements relative to an inertial reference system. FOG gyroscopes should ensure undisturbed measurement of angular speed irresoective of vibrations caused by the engine block work and the surge of the sea.

The most prospective in application to measure the rotational speed of the crankshaft could be professional FOG gyroscopes, if they had the appropriate range of the measured velocity, however, despite the potential technical capabilities widely available optical gyroscopes are not working at the required speed range.

The FOG gyroscope could be built on the base of typical telecommunications elements of fiber optic. Limitation to measurements in specific ranges of speeds can greatly simplify the design of the gyroscope and increase its resolution.

\section{References}

1. Łutowicz M.: unsteady angular speed of diesel engine crankshaft preliminary examination, 38th International Scientific Congress on Powertrain and Transport Means European KONES 2012, Journal of KONES POWERTRAIN AND TRANSPORT 20112 Vol.19, No4, 393-399,WARSAW 2012.

2. Morawski L., Sikora M., Application of the photo optic torquemeter to estimation of torque and rotational speed fluctuations on the propeller shaft of ship, 6th Slovak and Czech Conference SENSOR and SENSOR SYSTEM '97, KosicePresov 1997.

3. Piętak A., Borkowski W., Analiza pomiarów prędkości obrotowej i obliczeń przyspieszeń kątowych wału korbowego do celów diagnostycznych, SILWOJ'99, Jurata 1999.

4. Praca Zbiorowa, Indykowanie silników, AVL, 2004.

5. Wajand J. Pomiary szybkozmiennych ciśnień w maszynach tłokowych. Warszawa: Wydawnictwa Naukowo-Techniczne 1974. 